\title{
Correction to: Predictive reliability and validity of hospital cost analysis with dynamic neural network and genetic algorithm
}

\author{
Le Hoang Son ${ }^{1}$ (D) $\cdot$ Angelo Ciaramella ${ }^{2} \cdot$ Duong Thi Thu Huyen ${ }^{3} \cdot$ Antonino Staiano $^{2} \cdot \operatorname{Tran}_{\text {Manh Tuan }}^{4} \cdot$ \\ Pham Van $\mathrm{Hai}^{5}$
}

Published online: 12 May 2020

(C) Springer-Verlag London Ltd., part of Springer Nature 2020

\section{Correction to: \\ Neural Computing and Applications \\ https://doi.org/10.1007/s00521-020-04876-w}

In the original article, family name of one of the co-authors (Duong Thi Thu Huyen) has been missed in the online publication. The correct complete name should be Duong Thi Thu Huyen.

Publisher's Note Springer Nature remains neutral with regard to jurisdictional claims in published maps and institutional affiliations.

The original article can be found online at https:// doi.org/10.1007/s00521-020-04876-w.

Le Hoang Son

sonlh@vnu.edu.vn

Angelo Ciaramella

angelo.ciaramella@uniparthenope.it

Duong Thi Thu Huyen

duonghuyen@hmu.edu.vn

Antonino Staiano

antonino.staiano@uniparthenope.it

Tran Manh Tuan

tmtuan@tlu.edu.vn

Pham Van Hai

haipv@soict.edu.vn

1 VNU Information Technology Institute, Vietnam National University, Hanoi, Vietnam

2 Department Science and Technology, University of Naples Parthenope, Naples, Italy

3 Hanoi Medical University, Hanoi, Vietnam

4 Thuyloi University, Hanoi, Vietnam

5 School of Information and Communication Technology, Hanoi University of Science and Technology, Hanoi,

Vietnam 